\title{
Teste de conhecimento tático processual 3x3 com os pés: alternativa para a orientação esportiva
}

CDD. 20.ed. 796.011

http://dx.doi.org/10.1590/1807-55092015000400621

\author{
Henrique de Oliveira CASTRO* \\ J uan Carlos Perez MORALES* \\ Layla Maria Campos ABURACHID* \\ Pablo Juan GRECO* \\ *Escola de Educação \\ Física, Fisioterapia e \\ Terapia Ocupacional, \\ Universidade Federal \\ de Minas Gerais.
}

\begin{abstract}
Resumo
0 objetivo constituiu em avaliar o comportamento tático processual de crianças entre oito e 14 anos de idade em situação de jogo $3 \times 3$ com os pés, sem finalização. A amostra se compôs de 100 crianças (10,32 $\pm 1,45$ anos de idade). 0 presente instrumento apresentou um total de 16 itens a serem observados, sendo quatro itens para cada situação tática ou dimensão (jogador no ataque sem bola - JSB, jogador no ataque com bola - JCB, marcação ao jogador no ataque sem bola - MJSB, marcação ao jogador no ataque com bola - MJCB). No Coeficiente de Validação de Conteúdo (CVC), obtiveram-se valores satisfatórios para as quatro dimensões avaliadas. Estabeleceu-se a fidedignidade do instrumento pelo cálculo do índice Kappa inter e intra-avaliadores, demonstrando concordância entre os avaliadores. 0 instrumento idealizado apresenta índices de validade para avaliar o conhecimento tático processual de crianças nos domínios propostos para modalidades que utilizam dos pés como forma de jogo.
\end{abstract}

Palavras-chave: Iniciação esportiva; Jogos esportivos coletivos; Teste de conhecimento tático processual; Avaliação tática individual.

\section{Introdução}

Nos esportes e particularmente nos esportes coletivos, o comportamento do atleta, a realizaçáo de uma ação, será sempre um comportamento tático, isto é, toda ação esportiva é "um processo intencional dirigido, e regulado psiquicamente" ${ }^{\text {. Também }}$ se sabe que em toda açáo humana os processos são dinâmicos, motivados e realizados através de diferentes formas de comportamento dentro de um contexto social ${ }^{2}$. Isto é, quando o atleta se defrontar com problemas que exijam soluçóes num sistema de múltiplas referências, nos quais existem pressóes e solicitações fisiológicas e funcionais, condicionam-se e solicitam-se paralelamente também as suas funçóes psicológicas, especificamente os processos cognitivos.

Os jogos esportivos coletivos (JEC) apresentam um sistema de açôes complexas nas áreas motoras (condicional e/ou coordenativa), técnica, tática, cognitiva e psicossocial do participante ${ }^{3}$. Nos JEC, as equipes condicionam o tempo e o espaço na realização de tarefas opostas (ataque e defesa) $)^{4}$, e são marcados por situações condicionadas por restriçóes externas, por exemplo: posição e movimentos dos colegas e adversários, zona do terreno ou adversário a defender ou a atacar, distância do alvo, trajetórias e velocidade da bola, etc. A identidade desses jogos materializa-se na variabilidade das transiçóes de ataque e defesa, nas características da velocidade de jogo, na imprevisibilidade do contexto ambiental e na riqueza das variaçóes táticas ${ }^{5}$. Eles se caracterizam pelas açóes dos participantes em caráter aleatório, imprevisível e variável, frente à relação de cooperação-oposição estabelecida nas regras de jogo da modalidade que regulam o comportamento ${ }^{6-7}$. Nos JEC, durante a realização das habilidades técnicas é solicitado ao jogador à concretizaçâo de uma dupla tarefa, cognitiva e motora, sendo da conjugaçáo de ambas que ele elabora e concretiza as tomadas de decisóes ${ }^{8}$.

Aprender a jogar qualquer esporte envolve a interação de processos cognitivos como a percepção, a resolução de problemas, tomadas de decisão e 
resposta às informaçóes do ambiente. Nas diferentes formas de manifestação do esporte, por exemplo, jogando $3 \times 3$ na rua ou na escola em atividades de ensino, o oferecimento de procedimentos de jogar para aprender e aprender jogando estimulam o desenvolvimento da cognição, bem como da capacidade tática. O caráter situacional das ações no jogo exige respostas táticas, isto é, demandam processos cognitivos que conduzam à tomada de decisão sobre "o que fazer" e "como fazer" em cada situação ${ }^{6,9-10}$.

O conjunto das capacidades inerentes ao rendimento esportivo se inter-relaciona no momento da tomada de decisão, sendo que os processos cognitivos contribuem nessa função. Dentre os vários processos cognitivos presentes ao se realizar uma ação destacam-se a percepção, a atenção, a antecipação, a memória, o pensamento e a inteligência tática, processos que confluem na tomada de decisão ${ }^{10-11}$.

O desenvolvimento das capacidades cognitivas relaciona-se com uma elevada qualidade na prestação esportiva e permite, através do conhecimento armazenado na memória, que as tomadas de decisões sejam adaptadas à situaçáo de jogo que se defronta ${ }^{3}$. Embora a prática tenha importância reconhecida por alguns pesquisadores nas ciências do esporte, nem todas suas formas conduzem o praticante aos mesmos aprendizados ${ }^{12}$. Assim, torna-se importante conhecer as formas de aquisição de conhecimento tático processual e declarativo. Portanto é necessário identificar as

\section{Método}

\section{Participantes}

Participaram deste estudo 100 crianças (56 meninos e 44 meninas), cuja média de idade foi de 10,32 $\pm 1,45$ anos. Desses participantes, 35\% frequentam escolinhas esportivas, $18 \%$ participam de projetos sociais e $47 \%$ participam somente das aulas de Educação Física na escola. Em relação à prática esportiva sistematizada, 23\% praticam o Futsal, $18 \%$ o Voleibol e $59 \%$ outras modalidades, com um tempo de prática de menos de um ano (38\%), um ano $(6 \%)$, dois anos $(15 \%)$ ou mais de dois anos (41\%). A prática sistematizada dessas modalidades é realizada duas vezes por semana por $32 \%$, três vezes por $27 \%$ e mais de três vezes por $41 \%$ dos participantes, sendo em média 120 minutos por sessão. Além disso, 76\% dos participantes participam de competições e apenas $24 \%$ não participam. características dos processos de ensino-aprendizagemtreinamento (E-A-T) nos esportes para a mensuração do desenvolvimento, do nível de conhecimento tático processual (CTP) e declarativo (CTD) e das habilidades técnicas dos participantes durante esses processos ${ }^{13}$.

$\mathrm{Na}$ investigação científica dos esportes, se coloca a necessidade de estudo e formulaçáo de procedimentos de diagnóstico para determinar o nível de rendimento tático de atletas e equipes seja em uma competiçáo, durante o processo de treinamento, nas fases de formação, ou de alto rendimento. Entende-se paralelamente que testes são procedimentos avaliativos importantes no processo pedagógico de E-A-T para delimitar níveis de rendimento e consequentemente se oportunizar um adequado planejamento direcionado, por exemplo, à obtenção dos resultados nas competiçóes alvo. Portanto, cresce a necessidade de se desenvolver testes válidos e fidedignos para analisar o nível de conhecimento tático (declarativo e processual) dos atletas. Assim considerase uma forma de contribuiçáo para a práxis oferecer subsídios pedagógicos, especificamente na área dos processos avaliativos em relação aos parâmetros técnicotáticos que se apresentam nos JEC, sendo direcionados especificamente, nesse momento, para as modalidades que se utilizam os pés, como o futsal e o futebol.

Com isso, o objetivo do presente estudo foi avaliar o comportamento tático processual de crianças entre oito e 14 anos de idade, em uma situaçáo de jogo reduzido de três contra três $(3 \times 3)$ com os pés, sem finalização.

Este estudo foi aprovado pelo Comitê de Ética em Pesquisa da Universidade Federal de Minas Gerais sob o n. CAAE - 0734.0.203.000-12. Os participantes deste estudo, bem como os pais ou responsáveis pelas crianças e a direção dos estabelecimentos assinaram o Termo de Consentimento Livre e Esclarecido. Todos foram avisados dos objetivos e procedimentos do estudo e as crianças foram informadas que poderiam abandonar a participação no mesmo por qualquer motivo e a qualquer momento que desejassem.

\section{Procedimentos}

Os dados foram coletados entre os meses de agosto de 2011 e maio de 2012 em escolas públicas e particulares, bem como em escolinhas e clubes da cidade de Belo Horizonte, Minas Gerais, Brasil. 
Para avaliação e validação do teste de CTP foi realizado o jogo reduzido na situação de $3 \times 3$ aplicado com os pés, que considera a realização ou não de parâmetros comuns a modalidades que se utilizam os pés, mensurando-se a frequência ou não de comportamentos do participante no tempo de jogo em situaçóes de oposição direta, isto é, semelhante à situação de jogo ou competição. $\mathrm{O}$ teste se compóe de um jogo na constelação de três jogadores no ataque e três jogadores na defesa durante quatro minutos corridos, sem finalização, ou seja, objetiva-se a manutenção da posse de bola. $\mathrm{O}$ terreno de jogo consiste em um quadrado de $9 \mathrm{x} 9$ metros (equivalente a meia quadra de voleibol). $\mathrm{O}$ jogador na defesa pode antecipar ou interceptar, realizar o "desarme" ou tirar a bola que está dominada pelo jogador de ataque. Caso o defensor recupere a bola, a sua equipe passa a ser a equipe atacante. Para motivar a recuperação pela equipe de defesa, é contado o número de vezes que a equipe consegue roubar a bola, bem como para motivar a equipe de ataque, também é contado o número de passes trocados pelos mesmos. Ao reiniciar o jogo (primeiro passe), os defensores não podem atrapalhar a saída da bola, devendo todos permanecer nesse primeiro momento em posição de "estátua" (parados em pé, braços esticados junto ao corpo e mãos "coladas" às pernas).

A prática do futsal se dá essencialmente na quadra, portanto, para atender ao critério ecológico, o teste foi constituído no mesmo cenário da prática dessas modalidades, em espaços reduzidos e com materiais que normalmente estão disponíveis nas escolas, escolinhas, clubes, centros esportivos e outros. A estes critérios se agregou a necessidade de disponibilidade de procedimentos de avaliação padronizados, validados e fidedignos de baixo custo, com tarefas que sejam relativamente simples de serem realizadas, de explicação rápida e de fácil execução para o participante.

\section{Análise dos resultados}

Todos os testes aplicados foram filmados, conforme demonstrados na FIGURA 1. As análises foram realizadas por dois avaliadores (avaliação inter e intra) duas vezes cada, de acordo com uma grelha de avaliação dos itens propostos, onde cada ação esportiva proposta foi avaliada se foi realizada e quantas vezes foram realizadas. Essas análises foram feitas individualmente com todos os participantes do estudo.

$\mathrm{O}$ presente instrumento apresenta um total de quatro situaçóes de jogo ou dimensóes, descritas como: Jogador Sem Bola no Ataque (JSB), Jogador Com Bola no Ataque (JCB), Marcação ao Jogador Sem Bola (MJSB) e Marcação ao Jogador Com Bola (MJCB). Cada situação é avaliada por quatro itens, que serão descritos abaixo, na sessão de "validade de conteúdo".

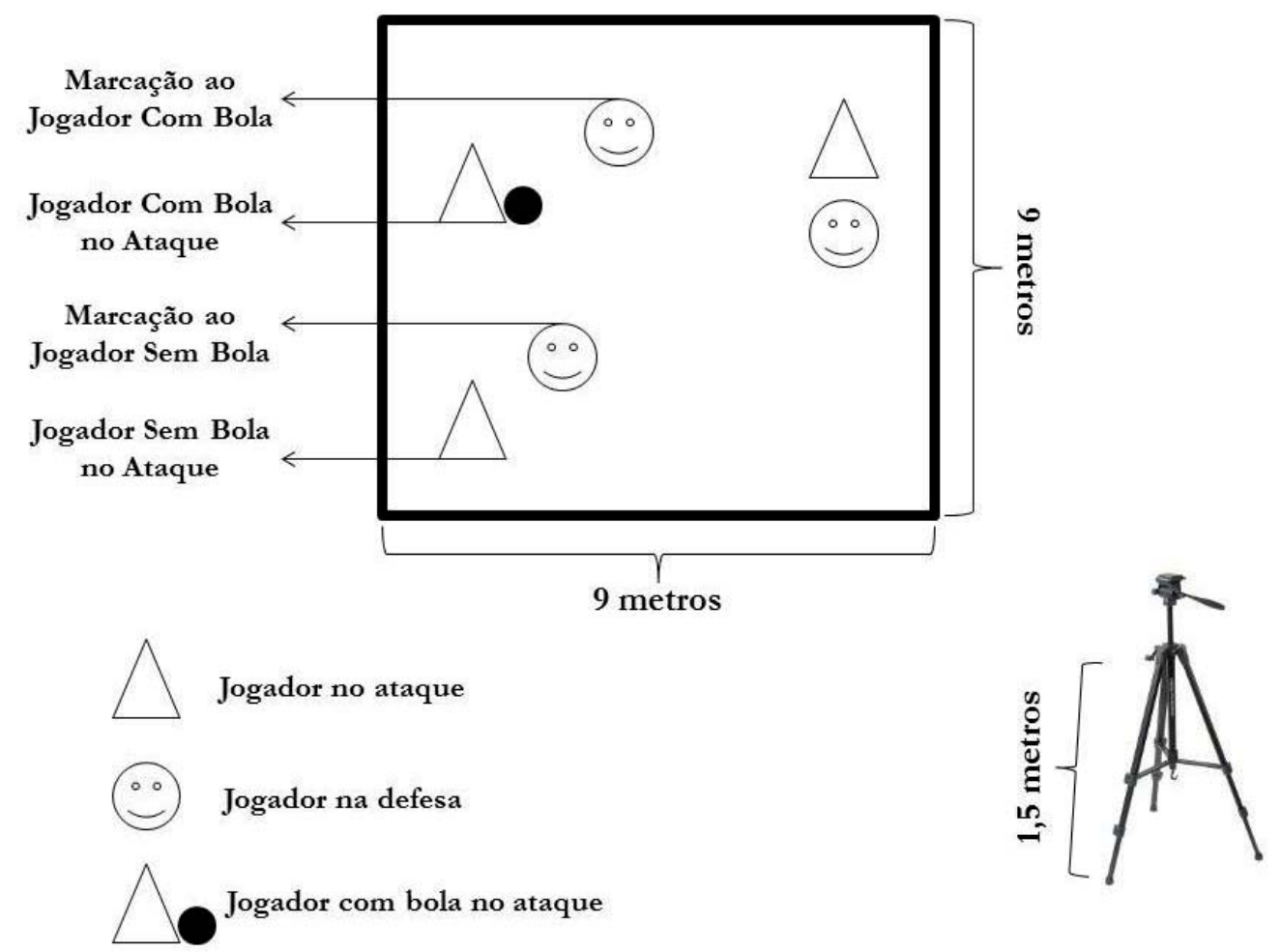

FIGURA 1 - Explicação do teste de conhecimento tático processual - orientação esportiva (TCTP - OE). 


\section{Resultados e discussão}

O processo de validação do teste para avaliação do conhecimento tático processual visando subsídios para uma orientaçáo esportiva (TCTP:OE), apresentou como resultados os seguintes produtos: processo de validação de conteúdo, análise fatorial, fidedignidade do instrumento e desempenho dos participantes.

\section{Validade de conteúdo}

O presente instrumento apresentou um total de 16 itens a serem inicialmente observados, sendo quatro itens para cada situação tática ou dimensão:

\section{1) Açóes técnico-táticas no ataque: jogador sem bola (JSB)}

1.1 Movimenta-se procurando receber a bola;

1.2 Movimenta-se sem intençáo de procurar a bola;

1.3 Procura espaços livres executando deslocamentos sem mudanças de direção e de velocidade;

1.4 Procura espaços livres executando deslocamentos com mudanças de direção e de velocidade.

\section{2) Açóes técnico-táticas no ataque: jogador com bola (JCB)}

2.1 Protege a bola com a intenção de não perder a posse ou para realizar um passe;

2.2 Conduz a bola controlando-a (fazendo ou náo finta) com a intenção de executar um passe;

2.3 Passa ao colega sem marcação e posiciona-se para receber;

2.4 Passa ao colega com marcação e posiciona-se para receber.

3) Açóes técnico-táticas na defesa: marcação ao jogador sem bola (MJSB)

3.1 Acompanha os deslocamentos do adversário que tenta se desmarcar;

3.2 Desloca-se para interceptar ou antecipar o passe;

3.3 Apoia aos colegas na defesa (cobertura) quando são superados pelo adversário;

3.4 Apoia ao colega na defesa quando o jogador com bola tem dificuldade para dominá-la.

4) Açóes técnico-táticas na defesa: marcação ao jogador com bola (MJCB)

4.1 Marca à distância mantendo o controle visual do jogador com bola;

4.2 Pressiona ao adversário e acompanha seus deslocamentos;
4.3 Pressiona ao adversário tentando tirar a bola ou induzindo ao erro;

4.4 Pressiona ao adversário levando-o para os cantos do campo de jogo.

Um dos procedimentos para validar o TCTP:OE, constituiu da aplicaçáo do coeficiente de validade de conteúdo (CVC) proposto por HernANDEZ-NIETO ${ }^{14}$. $\mathrm{O}$ mesmo foi calculado para cada um dos 16 itens $\left(\mathrm{CVC}_{\mathrm{C}}\right)$ e para o instrumento como um todo $\left(\mathrm{CVC}_{\mathrm{r}}\right)$. Para isso, foi necessária a participação de 11 juízes (quatro de basquetebol, três de handebol e quatro de futsal) com experiência mínima de 10 anos no processo de ensino - aprendizagem e treinamento nos jogos esportivos coletivos de invasão e com formação acadêmica mínima de mestrado na área de treinamento esportivo.

Os juízes utilizaram uma escala tipo Likert de 1 a 5 pontos para avaliar o nível de adequação dos 16 itens propostos, de acordo com a clareza de linguagem, pertinência prática e relevância teórica ${ }^{14}$.

A seguir apresenta-se o processo e as fórmulas para o cálculo do CVC, segundo Hernandez-Nieto ${ }^{14}$.

1) com base nas notas dos juízes, calculou-se a média das notas de cada item conforme proposto por Hernandez-Nieto ${ }^{14}(M x)$ :

$$
M_{x}=\frac{\sum_{i=1}^{J} x_{i}}{J}
$$

Onde $\sum \mathrm{x}_{\mathrm{i}}$ representa a soma das notas dos juízes e $J$ representa o número de juízes que avaliaram o item $^{14}$.

2) Com base na média, calculou-se o $C V C$ para cada item $\left(C V C_{i}\right)$ :

$$
C V C_{i}=\frac{M_{x}}{V_{\text {máx }}}
$$

Onde $\mathrm{V}_{\text {max }}$ representa o valor máximo que o item poderia receber ${ }^{14}$.

3) Realizou-se ainda o cálculo do erro $\left(\mathrm{P}_{\mathrm{ei}}\right)$, para descontar possíveis vieses dos juízes avaliadores ${ }^{14}$, para cada item:

$$
P e_{i}=\left(\frac{1}{J}\right)^{J}
$$


4) Com isso, o $C V C$ final de cada item $\left(C V C_{c}\right)$ foi assim calculado ${ }^{14}$ :

$$
C V C_{c}=C V C_{i}-P e_{i}
$$

5) Para o cálculo do CVC total do questionário $\left(\mathrm{CVC}_{\mathrm{t}}\right)$, para cada uma das características (clareza de linguagem e pertinência prática), utilizou-se:

$$
C V C_{t}=M c v c_{i}-M p e_{i}
$$

Onde $M c v c_{i}$ representa a média dos coeficientes de validade de conteúdo dos itens do questionário e Mpei, a média dos erros dos itens do questionário ${ }^{14}$.

$\mathrm{O}$ ponto de corte adotado para determinar níveis satisfatórios para clareza da linguagem, pertinência prática e relevância teórica foi de $\mathrm{CVC}_{\mathrm{c}} \geq 0,80$ para cada um dos itens e de $\mathrm{CVC}_{t} \geq 0,80$ para o instrumento no geral conforme recomendado na literatura da área ${ }^{15}$.

A TABELA 1 apresenta os valores de CVC encontrados para as propostas utilizadas.

TABELA 1 - Propostas do Coeficiente de Validade de Conteúdo (CVC) das modalidades futebol e futsal.

\begin{tabular}{lc}
\hline Proposta & CVC total \\
\hline Clareza de linguagem & 0,82 \\
Pertinência prática avaliada pelos juízes & 0,87 \\
Relevância teórica avaliada pelos juízes & 0,94 \\
\hline
\end{tabular}

\section{Análise fatorial}

Para verificação da adequação amostral para emprego da técnica da análise fatorial foi utilizado o índice $\mathrm{KMO}$ (Kaiser-Meyer-Olkin). Este índice varia de 0 a 1 . Valores menores que 0,5 indicam que não se deve utilizar a análise fatorial, sendo necessárias medidas de correção nos dados amostrais por meio de exclusão de variáveis ou inclusão de novas variáveis.

Além disso, também foi utilizada a prova de esfericidade de Bartlett para verificar se existem correlaçóes significativas $(\mathrm{p}=0,000)$ entre as variáveis e se o modelo fatorial é pertinente.

A seguir, realizou-se a análise das comunalidades, dos autovalores e dos percentuais de variância explicada para cada componente e para cada fator, assim como o percentual de variância total explicada. As comunalidades representam a proporção (quantidade) da variância de cada variável que pode ser explicada pelo modelo fatorial obtido. A partir das comunalidades é possível analisar se os fatores obtidos são suficientes para explicar todas e cada uma das variáveis incluídas na análise.

\section{Análise do jogador em situação de ataque sem bola e com bola}

A solução final proposta com quatro itens explica 68,48\% da variância e definem satisfatoriamente os dois fatores dentro das situaçóes de JSB e JCB.

$\mathrm{O}$ valor do $\mathrm{KMO}$ calculado com os quatro critérios de observação que apresentaram cargas fatoriais satisfatórias no modelo final resultante, foi de 0,564 , indicando que a técnica da análise fatorial pode ser utilizada para a amostra em questão. A prova de esfericidade de Bartlett demonstrou que existem correlaçóes significativas (Qui-quadrado = 105,096; $\mathrm{df}=6 ; \mathrm{p}=0,000$ ) entre as variáveis e o modelo fatorial é pertinente. Nas análises do JSB e JCB, a estimação de fatores pelo Método de Extração de Componentes Principais e Rotação Varimax com Normalização Kaiser, foram encontrados os seguintes valores para cada critério de observação: "Procura espaços livres executando deslocamentos sem mudanças de direção e de velocidade" = 0,794 (JSB); "Procura espaços livres executando deslocamentos com mudanças de direçáo e de velocidade" = 0,845 (JSB); "Protege a bola com a intenção de não perder a posse ou para realizar um passe" $=0,835$ (JCB); "Conduz a bola controlando-a (fazendo ou não finta) com a intenção de executar um passe" $=0,806$ (JCB).

Observa-se que os quatro itens definem satisfatoriamente os dois fatores dentro de JSB e JCB. Portanto, o fator 1 pode ser definido JCB e está composto pelos itens, "protege a bola com a intenção de não perder a posse ou para realizar um passe" e "conduz a bola controlando-a (fazendo ou não finta) com a intenção de executar um passe". O fator 2 pode ser definido como JSB composto pelos itens, "procura espaços livres executando deslocamentos sem mudanças de direçáo e de velocidade" e "procura espaços livres executando deslocamentos com mudanças de direção e de velocidade”.

\section{Análise do jogador em situação de defesa marcando o jogador sem bola e com bola}

A solução final proposta com quatro itens explica $76,52 \%$ da variância e define os dois fatores dentro das situações de MJSB e MJCB. Embora o fator 2 
tenha um alto valor de 0,969 , o modelo final ao momento de estabelecer a carga fatorial dos itens nos fatores propostos, estabelece satisfatoriamente os dois fatores. Nesse contexto, optou-se por seguir o modelo final resultante com dois fatores.

$\mathrm{O}$ valor do $\mathrm{KMO}$ calculado com os quatro itens que apresentaram cargas fatoriais satisfatórias no modelo final resultante, foi de 0,638 , indicando que a técnica da análise fatorial pode ser utilizada para a amostra em questão. A prova de esfericidade de Bartlett demonstrou que existem correlaçóes significativas (Qui-quadrado $=262,258 ; \mathrm{df}=6 ; \mathrm{p}=0,000$ ) entre as variáveis e o modelo fatorial é pertinente. No procedimento com o pé: análise do jogador em situação de MJSB e MJCB, a estimação de fatores pelo Método de Extração de Componentes Principais e Rotação Varimax com Normalização Kaiser, foram encontrados os seguintes valores para cada critério de observação: "Acompanha os deslocamentos do adversário que tenta se desmarcar" $=0,911$ (MJSB) ; "Apoia aos colegas na defesa (cobertura) quando são superados pelo adversário" $=0,813$ (MJSB) ; "Pressiona ao adversário e acompanha seus deslocamentos" = 0,752 (MJCB) ; "Pressiona ao adversário levando-o para os cantos do campo de jogo" = 0,893 (MJCB).
Observa-se que os quatro itens definem satisfatoriamente os dois fatores dentro das situaçōes de MJSB e MJCB. Portanto, o fator 1 pode ser definido como MJSB e está composto pelos itens: "acompanha os deslocamentos do adversário que tenta se desmarcar" e "apoia aos colegas na defesa (cobertura) quando são superados pelo adversário". O fator 2 pode ser definido MJCB e está composto pelos itens: "pressiona ao adversário e acompanha seus deslocamentos" e "pressiona ao adversário levando-o para os cantos do campo de jogo".

\section{Confiabilidade do instrumento}

A confiabilidade do instrumento proposto foi estabelecida pelo cálculo do índice Kappa inter -avaliadores (concordância entre observadores) e intra-avaliadores (teste re-teste em dias diferentes). Dessa maneira tanto para objetividade (inter-avaliadores) quanto para estabilidade (intra-avaliadores) foi considerada no mínimo $10 \%$ da amostra total deste estudo $^{16}$. O total de participantes avaliados foi de 100 em todas as situações e dimensões (JSB, JCB, MJSB e MJCB). A TABELA 2 apresenta os valores do índice Kappa calculados para cada uma das situaçóes. Embora os índices tenham sido baixos, em todos os casos a hipótese nula de não concordância foi rejeitada.
${ }^{*} p \leq 0,05 ;$

$\mathrm{JSB}=$ Jogador no ataque sem bola; $\mathrm{JCB}=$ Jogador no ataque com bola; MJSB = Marcação no jogador sem bola; MJCB = Marcação no jogador com bola.

TABELA 2 - Concordância inter-avaliadores e intra-avaliador, por meio do cálculo do índice Kappa.

\begin{tabular}{ccccccccc}
\hline & \multicolumn{2}{c}{ JSB } & \multicolumn{2}{c}{ JCB } & \multicolumn{2}{c}{ MJSB } & \multicolumn{2}{c}{ MJCB } \\
& Avaliador 1 & Avaliador 2 & Avaliador 1 & Avaliador 2 & Avaliador 1 & Avaliador 2 & Avaliador 1 & Avaliador 2 \\
\hline Avaliador 1 & $1^{*}$ & $0,142^{*}$ & $1^{*}$ & $0,138^{*}$ & $1^{*}$ & $0,226^{*}$ & $1^{*}$ & $0,717^{*}$ \\
\hline
\end{tabular}

\section{Análise de percentil conforme os critérios de observação (itens) validados}

TABELA 3 - Percentil conforme os critérios de observação (itens) validados pela análise fatorial.

\begin{tabular}{lc}
\hline $\begin{array}{l}\text { Critérios de observaçáo (itens) validados } \\
\text { pela análise fatorial }\end{array}$ & $\begin{array}{c}\text { Percentual } \\
(\%)\end{array}$ \\
\hline Total das açôes pela análise fatorial no JSB & 13 \\
Total das açóes pela análise fatorial no JCB & 16 \\
Total das açôes pela análise fatorial no MJSB & 14 \\
Total das açôes pela análise fatorial no MJCB & 13 \\
$\begin{array}{l}\text { Somatória de todas as ações validadas pela } \\
\text { análise fatorial }\end{array}$ & 44 \\
\hline
\end{tabular}

\section{Desempenho dos participantes a partir da análise de percentil}

TABELA 4 - Percentil do desempenho dos participantes a partir dos critérios validados pela análise fatorial.

\begin{tabular}{lcccc}
\hline $\begin{array}{l}\text { Desempenho nas } \\
\text { dimensóes observadas }\end{array}$ & $\begin{array}{c}\text { Fraco } \\
(\mathbf{\%})\end{array}$ & $\begin{array}{c}\text { Regular } \\
(\mathbf{\%})\end{array}$ & $\begin{array}{c}\text { Bom } \\
\mathbf{( \% )}\end{array}$ & $\begin{array}{c}\text { Muito } \\
\text { bom } \\
(\mathbf{\%})\end{array}$ \\
\hline Desempenho no JSB & 33 & 26 & 19 & 22 \\
Desempenho no JCB & 34 & 22 & 23 & 21 \\
Desempenho no MJSB & 42 & 15 & 23 & 20 \\
$\begin{array}{l}\text { Desempenho no MJCB } \\
\text { Somatória de todas }\end{array}$ & 51 & 29 & 20 & 0 \\
$\begin{array}{l}\text { as açóes validadas } \\
\text { pela análise fatorial }\end{array}$ & 28 & 23 & 25 & 24 \\
\hline
\end{tabular}


Durante o jogo se procede a interação dos elementos de cooperaçấo x oposição presentes nas diferentes situaçóes a serem resolvidas, isto possibilita que o aprendiz aprimore seu conhecimento tático específico da modalidade. Portanto, é de se destacar que conforme a proposta de E-A-T utilizada, caso ocorra a escolha por um processo com predomínio do método situacional, deve-se acrescentar a opção didática na qual se empregam atividades com situaçôes táticas em igualdade, superioridade numérica ou recorrendo ao uso do curinga (do tipo $3 \times 3,3 \times 2,3 \times 3+1$, etc.) utilizando os jogos reduzidos. Este tipo de atividade possibilita ao aluno a aquisição incidental do conhecimento técnico-tático necessário na modalidade e a oportunidade de solucionar adequadamente as diferentes situaçóes-problemas da competição.

Para Oliveira e Graça ${ }^{17}$, a utilização destas situaçóes de jogos reduzidos no processo de iniciação esportiva, condiciona positivamente a aquisição do conhecimento técnico-tático no aluno.

É importante destacar a operacionalizaçáo do desenvolvimento das capacidades cognitivas de percepção, atenção, antecipação e tomada de decisão ${ }^{18}$ de forma integrada dentro de um processo denominado do desenvolvimento da capacidade de jogo ao treinamento tático complementado pelo processo de aprendizagem motora ao treinamento técnico.

Esse resultado também enfatiza a importância da utilização do método situacional o qual, baseado na solução de problemas e por meio de situaçóes do contexto real do jogo, oportuniza positivamente a apropriação incidental de conceitos táticos, bem como parâmetros do comportamento tático criativo. Portanto, postula-se que uma forma adequada para contribuir no desenvolvimento da criatividade do atleta seja por meio do emprego de atividades que requisitem um amplo volume e distribuição da atenção, a utilização do pensamento divergente na geraçáo de ideias e do pensamento convergente na escolha da melhor alternativa para se encontrar soluçôes táticas adequadas às exigências situacionais que a própria competição, o próprio jogo impóem ao participante ${ }^{19}$.

Nos JEC solicita-se na situação de jogo que o atleta resolva os problemas que se lhe propóem situacionalmente, para tal é impreterível que o jogador execute uma ação técnica própria da modalidade esportiva ${ }^{20}$.

Acredita-se que o emprego de situaçóes de jogos reduzidos em constelaçôes de igualdade, superioridade numérica ou com uso do curinga oportunize ao praticante a capacidade de selecionar respostas adequadas. A criação de soluçôes (criatividade) e a escolha da ação mais adequada (inteligência) são parâmetros determinantes do nível de conhecimento técnico-tático do atleta ${ }^{21-23}$. Porém, além dos parâmetros táticos de oferecer-se e orientar-se, deve ser considerado que cada solução tática solicita uma escolha de uma técnica, isto é, se apresenta uma ênfase no segmento técnico. Assim, empregam-se nas condiçôes das tarefas determinados fundamentos técnico-táticos individuais e de grupo, seguidos de uma combinação de fundamentos técnicos.

$\mathrm{O}$ presente instrumento apresentou um total de 16 itens observados, sendo quatro itens para cada situação tática ou dimensão (JSB, JCB, MJSB e $\mathrm{MJCB})$. Todos os itens observados obtiveram valores de CVC para "Clareza de linguagem $=0,82$; Pertinência prática $=0,87$; Relevância teórica $=0,94$, valores estes acima do mínimo de 0,8 proposto por HeRnANDEZ-NIETO ${ }^{14}$.

Além disso, a solução final proposta com quatro itens explica $68,48 \%$ da variância e define satisfatoriamente os dois fatores constitutivos dentro das situaçóes de JSB (composto pelos itens "procura espaços livres executando deslocamentos sem mudanças de direção e de velocidade" e "procura espaços livres executando deslocamentos com mudanças de direção e de velocidade") e JCB (composto pelos itens "protege a bola com a intenção de não perder a posse ou para realizar um passe" e "conduz a bola controlando-a, fazendo ou náo a finta, com a intenção de executar um passe") $(\mathrm{KMO}=0,564)$. Na situaçáo de defesa, a solução final proposta com quatro itens explica $76,52 \%$ da variância e definem os dois fatores nas situaçôes de MJSB (composto pelos itens "acompanha os deslocamentos do adversário que tenta se desmarcar" e "apoia aos colegas na defesa - cobertura - quando são superados pelo adversário") e de MJCB (composto pelos itens "pressiona ao adversário e acompanha seus deslocamentos" e "pressiona ao adversário levando-o para os cantos do campo de jogo"). Embora o fator 2 tenha um alto valor de 0,969 , o modelo final ao momento de estabelecer a carga fatorial dos itens nos fatores propostos, estabelece satisfatoriamente os dois fatores $(\mathrm{KMO}=0,638)$.

A fidedignidade do instrumento proposto foi estabelecida pelo cálculo do índice Kappa inter- avaliadores (concordância entre observadores) e intra-avaliadores (teste re-teste em dias diferentes). Com os resultados obtidos mostrando a concordância entre os avaliadores. Conclui-se, portanto que o instrumento é valido para avaliar o conhecimento tático processual de alunos/atletas nos domínios das dimensóes propostas para modalidades que utilizam dos pés como forma de jogo, como o futebol e o futsal. 


\section{Abstract}

Tactical Knowledge Test Procedure 3X3 with feet: alternative to sporting orientation.

The objective was to evaluate the behavior of children tactical procedural between 8 and 14 years old in the game situation $3 \times 3$ with feet without finishing. The sample comprised 100 children $(10.32 \pm 1.45$ years old). This instrument has a total of 16 items to be observed, with 4 items for each tactical situation or size (player without the ball on offense - JSB player with ball in attack - JCB, marking the player without the ball on offense - MJSB, marking the player with the ball in attack - MJCB). In Coefficient Content Validation (CVC), we obtained satisfactory values for the four situations evaluated. The reliability of the instrument was established by calculating the Kappa inter and intra-rater, showing consistency among raters. The instrument has idealized presents validity indexes to evaluate the procedural tactical knowledge of children in the areas proposed for modes that use the feet as a form of play.

KeY WoRds: Sports initiation; Collective games; Tactical Knowledge Test Procedure; Individual tactical assessment.

\section{Referências}

1. Nitsch JR. Ecological approaches to sport activity: a commentary from an action-theoretical point of view. Int J Sport Psychol. 2009; 40:152-76.

2. Samulski DM. Psicologia do esporte: manual para a educação física, psicologia e fisioterapia. São Paulo: Manole; 2002.

3. Giacomini DS, Soares VO, Santos HF, Matias CJ, Greco PJ. Conhecimento tático declarativo e processual em jogadores de futebol de diferentes escalóes. Motricidade. 2011;7:43-53.

4. Garganta JM. (Re)fundar os conceitos de estratégia e táctica nos jogos desportivos colectivos, para promover uma eficácia superior. Rev Bras Educ Fís Esporte. 2006;20:201-3.

5. Tavares F, Greco PJ, Garganta J. Perceber, conhecer, decidir e agir nos jogos desportivos coletivos. In: Tani G, Bento JO, Petersen RDS. Pedagogia do desporto. Rio de Janeiro: Guanabara Koogan; 2006. cap.23.

6. Garganta J. A análise da performance nos jogos desportivos: revisão acerca da análise do jogo. Rev Port Ciênc Desporto. 2001;1:57-64.

7. Silva TAF, De Rose Junior D. Iniciação nas modalidades esportivas coletivas: a importância da dimensão tática. Rev Mackenzie Educ Fís Esporte. 2006;4:71-93.

8. Guerra I, Mesquita I. As regularidades na aplicação do remate por zona $4 \mathrm{em}$ voleibol em função das zonas alvo do ataque: estudo aplicado no campeonato do mundo de cadetes feminino (169-179). In: Mesquita I, Moutinho C, Faria R. Investigação em voleibol: estudos ibéricos. Porto: FCDEF-UP; 2003.

9. Thomas K, Thomas J. Developing expertise in sport: the relation of knowledge and performance. Int J Sport Psychol. 1994;25:295-312.

10. Silva MV, Greco PJ. A influência dos métodos de ensino-aprendizagem-treinamento no desenvolvimento da inteligência e criatividade tática em atletas de futsal. Rev Bras Educ Fís Esporte. 2009;23:297-307.

11. Matias CJAS, Greco PJ. Desenvolvimento e validação do teste de conhecimento tático declarativo para o levantador de voleibol. Arq Movimento. 2009;5:61-80.

12. Williams AM, Ford PR. Promoting a skills-based agenda in olympic sports: the role of skill-acquisition specialists. J Sports Sci. 2009;27:1381-92.

13. Pinho ST, Alves DM, Greco PJ, Schild JFG. Método situacional e sua influência no conhecimento tático processual de escolares. Motriz. 2010;16:580-90.

14. Hernández-Nieto RA. Contributions to statistical analysis. Bogotá: Universidad de Los Andes; 2002.

15. Cassepp-Borges V, Balbinotti MAA, Teodoro MLM. Tradução e validação de conteúdo: uma proposta para a adaptação de instrumentos. In: Pasquali L, organizador. Instrumentação psicológica: fundamentos e prática Porto Alegre: Artmed; 2010. p.506-20.

16. Tabachnick B, Fidell L. Using multivariate statistics. New York: Harper \& Row; 1989. 
17. Oliveira J, Graça A. O ensino do basquetebol. In: Graça A, Oliveira J, editores. O ensino dos jogos desportivos. Porto: Universidade de Porto, Faculdade de Ciências do Desporto e de Educação Física, Centro de Estudos dos Jogos Desportivos; 1995. p.61-94.

18. Greco PJ. Iniciação esportiva universal e escola da bola: uma integração das duas propostas. In: Garcia E, Lemos K, organizadores. Temas atuais X em educação física e esportes. Belo Horizonte: Health; 2005. p.33-62.

19. Greco PJ, Roth K, Schörer J. Ensino-aprendizagem-treinamento da criatividade tática nos jogos esportivos coletivos. In: Garcia E, Lemos K, editores. Temas atuais IX em educação física e esportes. Belo Horizonte: Saúde; 2004. p.52-63.

20. Greco PJ, Benda RN. Iniciação esportiva universal: da aprendizagem motora ao treinamento técnico. Belo Horizonte: UFMG; 1998.

21. French KE, Thomas, J. The relation of knowledge development to children's basketball performance. J Sport Psychol. 1987;9:15-32.

22. McPherson SL, Thomas J. Relation of knowledge and performance in boys tennis: age and expertise. J Exp Child Psychol. 1989; p.190-211.

23. Turner A, Martinek T. Teaching for understanding: a model for improving decision making during game play. Quest. 1995;44:44-63.

\section{Agradecimentos}

Os autores agradecem o apoio do CNPq.

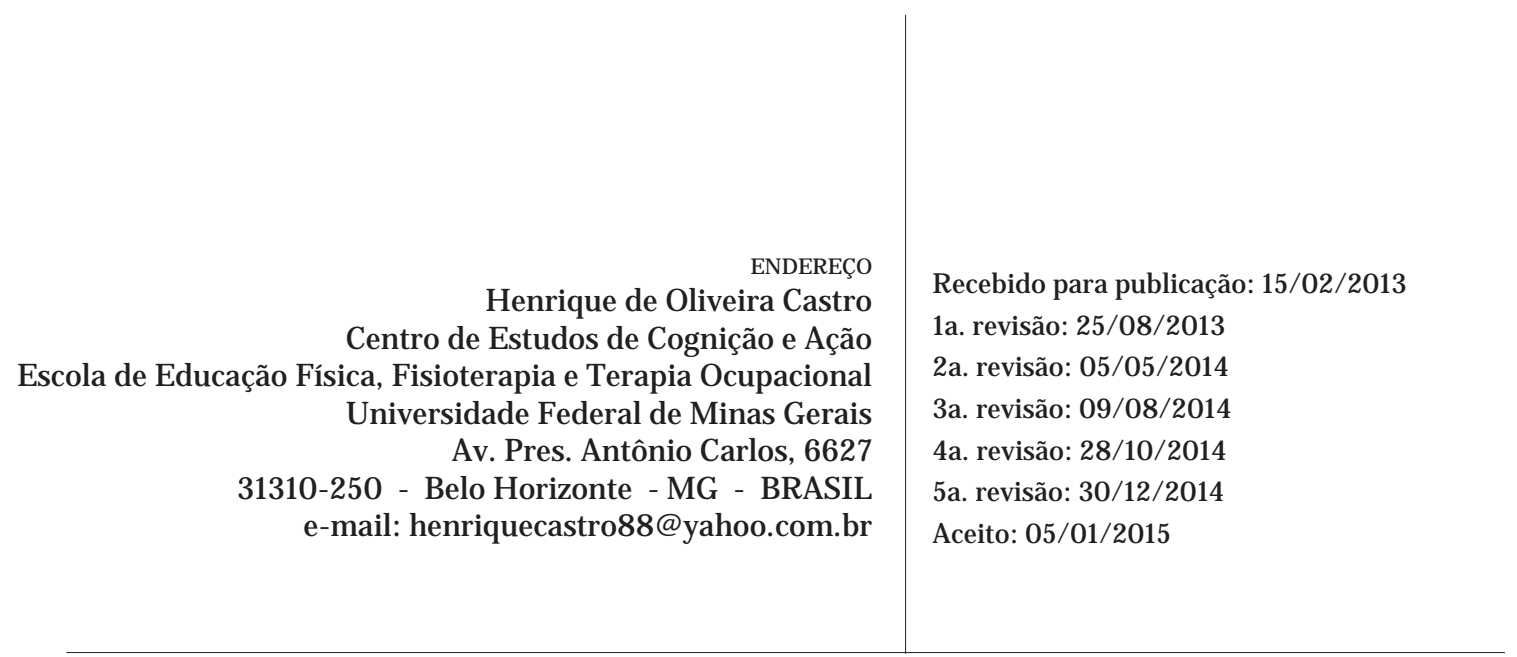

Rev Bras Educ Fís Esporte, (São Paulo) 2015 Out-Dez; 29(4):621-29 • 629 